\title{
«FILOSOFÍA» DE RUBÉN DARÍO, EMBLEMA DE LA RENOVACIÓN MODERNISTA
}

\author{
JOAQUÍN ROSES \\ Universidad de Córdoba
}

\section{Resumen}

«Filosofía» es uno de los poemas más breves y enigmáticos de Rubén Darío. El texto fue publicado por vez primera en Cantos de vida y esperanza (1905). En este artículo se propone una lectura de este poema disidente en la que se atienda a diversos niveles de análisis: configuración métrica, recepción crítica y creativa, estructuras lógicas, simbolismo y sentido.

Palabras clave: Rubén Darío, Métrica, Recepción, Símbolos, Animales, Astros, Música.

\begin{abstract}
"Filosofía" is one of the shorter and most enigmatic poems by Rubén Darío. This text was published for the first time in Cantos de vida y esperanza (1905). This article presents a reading of this dissident poem in which it attends to different analytical levels: metrical configuration, critical and creative reception, logical structures, simbolism and meaning.
\end{abstract}

Keywords: Rubén Darío, Meter, Reception, Symbols, Animals, Stars, Music.

\section{Introducción}

Hace unos meses leí Fragmentos un poco carbonizados del gran George Steiner, el último de sus libros meninos compuesto por una colección de ocho brevísimos ensayos. También son ocho los versos de «Filosofía» (1905), el breve poema de Rubén Darío cuyo análisis e interpretación abordo en estas páginas. Comentar textos que han cumplido más de cien años puede ser un placer o un suplicio: opto por la disciplina pero también por el gozo que supone 
establecer un diálogo fecundo entre textos antiguos y textos de nuestros días. Curiosamente, el primero de los ensayos de Steiner, titulado «Cuando el rayo habla, dice oscuridad», abunda en conexiones sugerentes con el poema de Darío. Se afirma allí:

Toda forma y todo código, orgánico o construido, puede comunicar información, producir emoción. Nuestra misma existencia es una lectura constante del mundo; un ejercicio de desciframiento, de interpretación dentro de una cámara de eco que tiene infinidad de mensajes semióticos. Pero esto no necesariamente implica claridad; no necesariamente asegura significado con su potencial y su rendición de paráfrasis y traductibilidad (12).

Sobre la existencia y su imposibilidad de explicación racional trata «Filosofía», uno de los textos de Darío de los que no se conoce publicación anterior en periódico o revista y que reproduzco a continuación:

Saluda al Sol, araña, no seas rencorosa.

Da tus gracias a Dios, oh, sapo, pues que eres.

El peludo cangrejo tiene espinas de rosa

y los moluscos reminiscencias de mujeres.

Sabed ser lo que sois, enigmas siendo formas;

dejad la responsabilidad a las Normas,

que a su vez la enviarán al Todopoderoso...

(Toca, grillo, a la luz de la luna, y dance el oso) ${ }^{1}$.

El poema aparece como número XI en la sección «Otros poemas» de Cantos de vida y esperanza (1905). El manuscrito, como tantos otros de Darío, se encuentra en la Biblioteca del Congreso de Washington dentro de la caja que contiene los 125 documentos del archivo denominado Juan Ramón Jiménez Papers. De todos ellos la mayoría pertenece al nicaragüense. El Premio Nobel español los donó entre 1949 y 1954; dicho regalo fue ampliado con documentos aportados por José María Longo en 1982. La División de Manuscritos de la Biblioteca los catalogó y describió en 1984 y actualizó la información en 2010. Según anota Julio Ortega, un grupo de investigación de la Universidad de Salta liderado por I. Rossi de Fiori publicó en México una edición facsimilar y con variantes de los manuscritos basada en la transcripción de un microfilm (en Darío, 2007, 1292-1293).

Como indica José María Martínez en la nota a su edición del poema, el manuscrito "presenta tachada la cifra III, que parece escrita por mano de Darío y que se sustituye por la cifra XI, escrita por otra mano diferente» (en Darío, 1995, 413). Según está documentado, fue Juan Ramón Jiménez quien

1. Cito por la edición de José Carlos Rovira (Darío, 2011, 446-447). 
preparó el libro para la edición; por ello no sería extraño que él mismo hubiera rectificado el orden asignado por Darío en la sección «Otros poemas» (tras los dos «Retratos» y el poema «Por el influjo de la primavera»), para situarlo mucho después, como poema undécimo de esa sección.

Las ediciones de 1905 y 1907 presentan algunas variantes con respecto al manuscrito que han sido repetidas en numerosas ediciones de bolsillo e incluso en la de Poesías preparada por Ernesto Mejía Sánchez en 1952. Estas son el uso de la minúscula en «Sol» (v. 1), el imperativo en singular del verso 6 («Deja» por «Dejad») y la desaparición del signo final de exclamación en el verso 8 (Martínez, en Darío, 1995, 413). El texto que utilizo como fuente es muy cercano al del manuscrito, aunque suprime los signos de exclamación de la apelación al sapo (que sí recoge Martínez, quien sigue el texto autógrafo). Rovira suprime también el signo de exclamación al final del poema y, como casi todos los editores recientes salvo Martínez, tampoco mantiene las mayúsculas iniciales de cada verso.

\section{1. «Filosofía», poema disidente}

Aunque sea irrelevante para este ensayo, debo decir que «Filosofía» ha sido siempre uno de mis poemas predilectos de Darío y me sorprende que no haya sido mejor estudiado. Puede ser calificado, por muchas razones, como poema disidente. Para empezar, no se trata del Darío convencional que cantaba «con aquella locura armoniosa de antaño», pero eso es normal a las alturas de 1905, como lo justifica el propio autor en su poema «De otoño». Es lógico que en un libro como Cantos de vida y esperanza, donde, aparte de las experimentaciones con el encabalgamiento, con frecuencia se rompe con la isometría y la isorritmia de muchos poemas de Prosas profanas, aparezcan poemas como este. Como se verá más abajo, las peculiaridades referentes al cómputo silábico y al ritmo son relevantes y no han sido debidamente analizadas.

Tampoco este poema representa la convención cromática dariana que admiramos, por supuesto, en Prosas profanas, pero también en numerosos poemas de Cantos de vida y esperanza. El despliegue del color se encomienda aquí solo a los sustantivos, y se reduce a la construcción en anillo basada en el contraste del inicio («Sol») con el final del poema («luz de la luna»). Además, los adjetivos o construcciones adjetivales son muy escasos («peludo», «de rosa», «de mujeres», «de la luna»). Si en poemas del mismo libro, como «Leda» $\mathrm{O}$ «La dulzura del ángelus», se devana un hilo cronológico para expresar el transcurso de los diversos momentos del día mediante el empleo de gamas cromáticas, en «Filosofía» se marca tenue y levemente un viaje de la luz a la sombra, sin matices intermedios. Nos hallamos, por tanto, ante un poema 
verbal y sustantivo donde predomina lo conceptual, lo interior enigmático frente a las formas accesorias u ornamentales, por utilizar como referencia el mismo verso 5: «Sabed ser lo que sois, enigmas siendo formas».

Y es también un poema extraño, rupturista, ambiguo (me atrevería a decir que actual), como se irá viendo, por el contraste absoluto que mantiene con poemas de tan hondo pesimismo e introspección como los dos «Nocturnos[s]» o «Lo fatal». Se expresa en él la creencia en la mera cualidad del ser, sin más razonamientos o preocupaciones, la decidida opción por el puro vivir con independencia de lo aparente. Es emblema, por eso, de un nuevo comienzo, una nueva faceta de la filosofía de vida de Darío quien, atormentado y «triste de fiestas», se refugia en este tipo de planteamientos espirituales procedentes, eso sí, del esoterismo y los diversos sincretismos espirituales que predominaban en la sección «Las ánforas de Epicuro» de la segunda edición de Prosas profanas (1901). No es necesario aplicar ningún método científico para saber esto, sino leer con atención y profundidad la obra completa de Darío.

\section{Configuración métrica}

Y aunque no se trate de un método estrictamente científico, sí es necesario desplegar cierta habilidad analítica para detectar la técnica métrica y los juegos acústicos que enriquecen la construcción hímnica de «Filosofía».

Los modernos editores presentan estos ocho versos alejandrinos formando una única estrofa, mientras que en ediciones anteriores son distribuidos en dos estrofas de cuatro. En cualquier caso, siendo una estrofa de ocho versos de arte mayor, no sigue ni el esquema de la antigua copla de arte mayor ni el de la italianizante octava real, ya que su esquema de rimas corresponde a la unión de un serventesio con dos pareados (ABABCCDD).

Como cuestiones menores en el cómputo silábico hay que señalar el final agudo del primer hemistiquio en los versos 2 («Dios»), 5 («sois») y 7 («enviarán»), lo cual no resulta nada extraordinario y que no hayamos oído ya desde las primeras manifestaciones modernistas. También puede señalarse la posición de la cesura tras las dos primeras sílabas de una palabra poliacentuada, como sucede en el verso 4 («rèmi / niscéncias»), pues de otro modo es imposible formar el alejandrino. Pero estas rupturas de palabras por la cesura (con el uso a veces de la sílaba anterior a la cesura como final agudo para añadir una sílaba al hemistiquio) era ya algo habitual que encontrábamos en los poemas de la primera edición de Prosas profanas (1896).

Análisis especial merecen, sin embargo, los versos 6 y 8 . En el 6 («dejad la responsabilidad a las Normas»), cuya cesura se sitúa también después de las tres primeras sílabas de la palabra «responsa / bilidad», hay que aplicar 
doble acentuación al polisílabo (como antes en «rèmi / niscéncias»), pero no acentuando secundariamente en grave («respònsa / bilidád»), sino en aguda («responsà / bilidád»), con lo que obtendríamos, como en los casos de los versos 2, 5 y 7 , un nuevo final agudo de primer hemistiquio para formar, y tampoco es posible de otra manera, el verso alejandrino. El verso 8, «(Toca, grillo, a la luz de la luna, y dance el oso)», es el más complejo de todos, pues el único modo de adaptarlo al esquema rítmico del alejandrino consiste en marcar la cesura tras «de», pero utilizando una pequeña licencia que consistiría en no aplicar la regla de que todo monosílabo funciona como aguda, pues si lo hiciéramos obtendríamos un hemistiquio octosilábico; el esquema rítmico quedaría, por tanto, del siguiente modo: «(Tóca, gríllo a la lúz de / la lúna, y dánce „el óso)», como si las palabras «luz»y «de» formaran una sola palabra grave «luz-de».

Por lo que se refiere a las cláusulas rítmicas, las regularidades más sensibles al oído serían las siguientes: a) ritmo trocaico perfecto en el verso 1 («Salúda al Sól, aráña, / no séas rèncorósa»), con acentuación doble en el único polisílabo del verso; b) predominio trocaico también en el verso 4 («y lòs molúscos rèmi / niscéncias dè mujéres»), que puede ser leído como verso trocaico con gran anacrusis de cuatro sílabas aunque con posibilidad de acentuación secundaria en los dos monosílabos presentes; c) clausulas trocaicas algo más forzadas en el verso 5 («Sabéd ser lò que sóis, / enígmas siéndo fórmas»), siempre que acentuamos en «sabéd» y en el monosílabo «lò», teniendo en cuenta la presencia del antirrítmico de «ser»; de no realizarse esta ejecución tendríamos un primer hemistiquio dactílico y un segundo trocaico («Sabed sér lo que sóis, / enígmas siéndo fórmas»); d) frente a este predominio de las cláusulas trocaicas, los periodos rítmicos dactílicos vertebran los versos 3 («El pelúdo cangréjo / tiene espínas de rósa») y 6 («dejád la responsá / bilidád a las Nórmas»), con clausula tetrasilábica, en este último caso, en primer hemistiquio; e) el verso 2 combina un primer heptasílabo dactílico con un segundo trocaico con acento secundario en «puès» («Da tus grácias a Diós, / oh, sápo, puès que éres») sin hacer sinalefa, aunque podría acentuarse también el imperativo, con lo que tendríamos un ritmo mixto en el hemistiquio, y, como puede comprobarse resulta muy expresivo el antirrítmico de la exclamación; f) el verso 7 funciona igual que el 2 pero con triple acentuación en el polisílabo («que a su véz la enviarán / al tòdopòderóso»); g) el 8 es tan variado rítmicamente como el 2 y el 7 , pero el primer hemistiquio es mixto de trocaico y dactílico y el segundo es claramente trocaico, con lo que los periodos rítmicos trocaicos quedan especularmente en los extremos del verso: «(Tóca, gríllo a la lúz de / la lúna,y dánce_el óso)». 
En cuanto al timbre, puede señalarse el predominio de vocales oscuras con rentabilidad máxima de la «o» en los extremos del verso 1 , sin olvidar la presencia de la «a» en posiciones extremas y central. Algo inverso sucede en el verso 2, con la posición central de la «o» y el juego alterno con la «a». Obsérvese también el predominio de la cerrada «u» en posiciones acentuales («Salúda» «pelúdo» «molúscos»). El arco vocálico es más abierto en los versos 5 y 6 y va cerrándose progresivamente a medida que nos acercamos al final del poema. Todo ello aparece reforzado por el juego con las rimas «osa» y el eco que se les hace en el pareado final («oso»). Una circularidad fónica coherente con otras construcciones semánticas en anillo, como la que hemos señalado antes con la aparición del sol y la luna al principio y al final del poema respectivamente. Y en todo el poema, el uso de las silbantes, entre las que incluyo las fonológicamente interdentales, pues Darío, como la inmensa mayoría de los hispanohablantes, seseaba. Pueden ponerse como ejemplos destacados los versos $1,2,4$ y 5 , aunque el resto también las contiene parcialmente.

Por último, bien sabemos que Cantos de vida y esperanza es un libro donde el uso del encabalgamiento adquiere una importancia definitiva, aunque todo esto ya se auguraba, como tantas otras cosas, en las adiciones de 1901 a Prosas profanas. En cambio, en este poema, tan disidente de otros por varias razones, predomina la esticomitia, y no aparecen encabalgamientos abruptos, como sí sucederá, por ejemplo, en los dos «Nocturno[s]» o en «Lo fatal».

\section{Recepción crítica}

Casi por norma y también por respeto al testimonio del autor, todo asedio a los poemas de Darío suele partir de las palabras que el propio poeta les dedica en su «Historia de mis libros»: «En "Filosofía" se comprende la justeza de la obra natural y de la divina razón, contra las feas y dañinas apariencias» (1989, 77).

La sensibilidad, el rigor, la erudición y los aciertos del estudio de Arturo Marasso, Rubén Darío y su creación poética (1934), obligan también a mencionarlo. Al poema «Filosofía» se le dedica en ese estudio poco más de una página escrita hace ya más de 80 años; líneas que, junto a otros muchas suyas, deberían ser más citadas por algunos estudiosos actuales de Rubén Darío, no siempre honestos en el reconocimiento. Dice allí Marasso que este poema «es un brote del espíritu medieval que perdura en Darío. El poeta conoce bestiarios de la Edad Media y maneja, como erudita enciclopedia, La Catedral de Huysmans» (222-223) y que Darío contrapone este poema a «Anagke» de Azul... (223). Debe recordarse que en ese último poema el canto hímnico y 
celebratorio de la paloma es abruptamente interrumpido por la voracidad del gavilán, lo que hace reflexionar a Dios «que cuando creó palomas / no debía haber creado gavilanes». (Darío, 2011, 315). Será preciso volver, más adelante, a los comentarios de Marasso sobre algunas de las criaturas que aparecen en el poema. Me interesa ahora reparar en el final de su breve comentario, donde afirma:

A Darío le preocupó el reparto de los dones que han hecho los dioses a los seres y a los hombres; en Los Cisnes, dice que se dio a la alondra la luz del día, se dio sabiduría a los búhos, y melodía al ruiseñor, etc.; en Azul recuerda la época en que las hadas repartieron sus dones entre los mortales. Este mito del reparto se encuentra, en distintas formas, en Píndaro, en el Protágoras de Platón, en Schiller, en los cuentos de hadas (224).

La alusión a $A z u l \ldots$ se refiere al cuento «El velo de la reina Mab» en cuyo segundo párrafo leemos: «Por aquel tiempo, las hadas habían repartido sus dones a los mortales» (2011, 241). Como ha estudiado, entre otros, José María Martínez, una de las fuentes de este cuento es la descripción que Shakespeare pone en boca de Mercurio en la escena IV del Acto I de Romeo y Julieta (en Darío, 1995, 313). Y es a partir de esta referencia donde las conexiones del cuento con el poema «Filosofía» me parecen más sugerentes, no tanto, como afirma Marasso, por el motivo del reparto de los dones a los seres vivos, sino por las coincidencias entre la carroza de la reina Mab y algunos de los animales que aparecen en el poema que comentamos. Aunque ninguna de estas alusiones a animales figura en el cuento de Azul..., en el parlamento de Mercurio sí podemos leer que los radios de las ruedas de la carroza están formados por largas patas de araña, que las riendas son de finísima telaraña, las colleras de húmedos rayos de luna y su látigo de un hueso de grillo².

Por otra parte, y para continuar con los diálogos de siglo a siglo, el motivo del reparto de los dones es abordado también por George Steiner en su breve ensayo «Hay leones, hay ratones», perteneciente a Fragmentos un poco carbonizados. Dice allí que «[1]a gran maestra de la democracia es la muerte» (27) y que

2. Aunque José María Martínez aporta la libérrima traducción del parlamento de Mercurio que hizo en su día Menéndez Pelayo (en Darío, 1995, 313), lo que me puso sobre la pista de estas conexiones fue la cita del fragmento utilizada por Italo Calvino para demostrar que en el sueño de la reina Mab se funden el atomismo lucreciano, el neoplatonismo renacentista y la celtic-lore como claves de la levedad literaria (2010, 33), característica que Calvino asocia al «nuevo milenio» y que, soberbiamente, está vertebrando el poema de Darío. 
[e]l mundo de los minusválidos, los ciegos o los lisiados no es el de los indemnes. El de los desfigurados y los feos no es el de los hermosos. Los privilegios de la belleza, su arrogancia — aunque sea inconsciente-, son despiadados (27).

Todo ello para terminar preguntándose «i[c]ómo debemos hallar sentido a la abierta injusticia de la distribución de talento entre los seres humanos?» (31). Este poema de Darío es una desconsolada respuesta a esa pregunta cuyas referencias ideológicas se sustentan en el conformismo católico presente, por ejemplo, en los principios defendidos por Calderón en El gran teatro del mundo. Al fondo, como debe ser, nutre toda esta dinámica el problema filosófico del mal, pero a eso volveremos luego acompañados de arañas y sapos.

A «Filosofía» no le dedica su atención crítica Pedro Salinas en su importante estudio sobre La poesía de Rubén Darío (1948). Sí alude a él Cathy Login Jrade, a la zaga de las observaciones de Marasso, en el capítulo de su libro (1986) dedicado a «[e]l pitagorismo esotérico en la idea dariana del universo». En las dos medias páginas que le dedica al poema, termina concluyendo «que es afinándose con el ritmo de la vida y con la música de las esferas como puede lograrse la armonía universal» (74-75). Otros dos cuartos de página le dedica Louis Bourne, donde quizá lo más destacado es la aseveración obvia de que «las formas neoplatónicas son para él [Darío] manifestaciones de un enigma del universo», lo cual conecta el verso 5 («Sabed ser lo que sois, enigmas siendo formas») con el 53 del «Coloquio de los centauros», donde Quirón afirma que «toda forma es un gesto, una cifra, un enigma» (257-258). La relación con el extenso poema de Prosas profanas ya había sido establecida en 1982 por Giovanni Allegra (1986, 186 y 199), al vincular con acierto el mismo verso con estos otros del «Coloquio de los centauros» puestos también en boca de Quirón: «Ni es la torcaz benigna, ni el cuervo protervo: / son formas del Enigma la paloma y el cuervo» (vv. 89-90).

Quien ha dedicado más páginas al estudio de este poema (casi tres) ha sido A. R. Van den Broek Chávez en Esoterismo y modernismo: Ruben Darío y Antonio Machado, tesis defendida en Amsterdam en 2001 bajo la supervisión de Germán Gullón, en la cual encontramos un capítulo titulado «Metafísica y esoterismo en Darío» donde se aborda el estudio parcial de «Filosofía» dentro del apartado «La divinización del mundo: enigmas siendo formas» (117-119). Haré referencia a algunas de sus observaciones sobre los animales que aparecen en el poema cuando examine su simbología.

Para finalizar este sucinto estado de la cuestión debe mencionarse el sugerente analisis que James Irby publica del también brevísimo poema «Ibis». Allí contrapone el «tono categórico y celebratorio [de "Filosofía"] en lugar 
del tono misteriosamente reservado de "Ibis". Una jubilosa exhortación en lugar de una sigilosa advertencia».

\section{Recepción creativa}

Tras esta escueta recepción crítica, el seguimiento de la recepción creativa del poema nos ofrece algunas curiosidades. Era casi obligado que se relacionara este texto de Darío con «Los sapos» de José Juan Tablada: «Trozos de barro, / por la senda en penumbra / saltan los sapos», y así lo consigna Seiko Ota en su libro José Juan Tablada: su haikú y su japonismo, aunque la conexión no creo que vaya más allá de la mención del animal. También Sara Saz cita el mismo texto de Tablada, pero sin relacionarlo con Darío. Sí es interesante el testimonio que recoge de Jorge Carrera Andrade, quien «no rehusó convertir en temas poéticos aspectos más bien desagradables de la naturaleza»: «Descubrí [cita un testimonio de Andrade] que los seres feos cumplen también, a su modo, una tarea bella, y que el sapo, el moscardón, el gusano, son otras tantas cifras de la clave secreta del universo» (194).

José Carlos Rovira vio también con agudeza cómo la lectura de este poema de Darío pudo influir en algunas composiciones de Miguel Hernández escritas en su etapa inicial «como en el muy juvenil "Lagarto, mosca, grillo, reptil, sapo, asquerosos / seres, para mi alma sois hermosos", donde [dice Rovira] estamos leyendo seguramente una transformación de "Filosofía"» (214215). Me permito añadir que incluso el empleo de la rima «osos» parece un eco también del poema de Darío.

Para terminar este apartado, conviene dar cuenta de la fortuna que el primer verso del poema («Saluda al Sol, araña, no seas rencorosa») ha tenido en varios escritores mexicanos o vinculados a México. El primero, quizá, Octavio Paz, quien lo reproduce, en un giro amargo e irónico, al final de «Elegía interrumpida» (144-147), poema en que rememora la muerte de algunos familiares suyos. La primera publicación del texto data de 1948 y pertenece a «Calamidades y milagros», segunda sección de Libertad bajo palabra (1960):

Montón de días muertos, arrugados

periódicos, y noches descorchadas

y en el amanecer de párpados hinchados

el gesto con que deshacemos

el nudo corredizo, la corbata,

y ya apagan las luces en la calle

— saluda al sol, araña, no seas rencorosa-

y más muertos que vivos entramos en la cama.

Es un desierto circular el mundo,

el cielo está cerrado y el infierno vacío (146-147). 
En el marco de varias páginas ensayísticas donde se compara el concepto de juventud en Darío y en Cernuda, siendo «divino tesoro» la suya propia para el nicaragüense y tesoro anhelado la ajena para el español, Tomás Segovia menciona ese mismo verso y los tres que le siguen para ilustrar el alcance de esa diferencia. Afirma Segovia que esos versos parecen estar escritos ex profeso para Cernuda, pero que la respuesta de ambos poetas ante la pérdida de la juventud y la exclusión que conlleva es muy distinta, más sosegada la de Darío y más amarga la de Cernuda, lo cual se formaliza incluso en el sentido mismo de dos títulos de madurez: Cantos de vida y esperanza frente a Vivir sin estar viviendo (92 ss.).

Carlos Monsiváis, en su libro Días de guardar, no solo utiliza el primer verso como título del apartado correspondiente al 15 de noviembre de 1969 (307-320), sino que lo vuelve a citar al final del mismo. El texto es una crónica de la clausura de la Convención del Partido Revolucionario Institucional celebrada en esa fecha en que se produce la toma de protesta de Luis Echeverría Álvarez, candidato a la presidencia para el período 1970-1976. Casi al final, Monsiváis escribe, también con ironía ante la llegada del candidato:

Frente a la euforia, el triturante espíritu de conquista y retención que desplaza cualquier otro sentimiento, que desecha los ánimos fluctuantes y enconados, miro, como en exhalación, como escrita en una mano en la pared (mientras su mano compañera agita un banderín) una frase, que perteneció a Rubén Darío y que Octavio Paz insertó en uno de sus poemas: Saluda al sol, araña, no seas rencorosa (319).

Rosario Castellanos, por último, también utiliza el primer verso de «Filosofía» en uno de los fragmentos de «Diálogos con los hombres más honrados», incluidos en Poesía no eres tú (1972):

«Saluda al sol, araña, no seas rencorosa».

¿Por qué habrías de serlo si tienes un rincón

y una tela que hacer y el instinto seguro

del tejedor que teje sin preguntarse nunca.

ni el motivo ni el fin? (318).

Este breve poema desarrolla mejor que ninguna otra cita una de las ideas centrales del texto de Darío: la necesidad de vivir y de crear sin preguntarse nunca por las razones o el resultado de nuestra existencia.

\section{Estructura lógico-sintáctica y esquema comunicativo}

Antes de examinar los valores simbólicos de las presencias astrales y animales que aparecen en el poema, conviene ahora reparar, aunque muy brevemente, en la estructura lógico-sintáctica del poema y su esquema comunicativo. 
Todo el texto funciona como una orden o mandato, de ahí que cinco de los ocho versos comiencen con imperativos («saluda», «da», «sabed», «dejad», «toca») y que en los hemistiquios finales de los versos primero y último aparezcan subjuntivos con valor de imperativo («no seas», «dance»).

En el esquema comunicativo, lo más significativo es la variabilidad de los destinatarios del mandato, por cuanto el sujeto poético se dirige en los versos 1 y 2 a seres particulares individualizados (la araña y el sapo) mientras que los receptores de las órdenes son colectivos en los versos 5 a 7 (todos los seres anteriores en su conjunto, que son formas con función enigmática). La estructura imperativa se quiebra en los versos 3 y 4 , donde se enuncian, sin más, las características de otros dos seres (el cangrejo y los moluscos). Por último, en el verso final, reaparece la apelación directa e individualizada en forma de mandato al grillo y al oso.

\section{Lectura (esencialmente) simbólica}

\section{1. «Saluda al Sol, araña, no seas rencorosa»}

En su nivel simbólico, el poema funciona unitariamente como una hierogamia, o sea, un matrimonio entre cielo y tierra formalizado aquí por la unión del Sol (arriba en v. 1) y la luna (abajo en v. 8). La oposición se da también entre lo activo y lo pasivo, tradicionalmente asociado esto último a la luna como receptora de la luz solar (Cirlot, 290, 421-422). El sintagma «luz de la luna» manifiesta el carácter dependiente de esta en la jerarquía de los astros.

Como afirmé más arriba, la paleta cromática es simple, pues se limita al sulfúrico oro del Sol y a la mercurial plata de la luna. Sería ocioso y plomizo explicar ahora por qué el Sol representa simbólicamente la divinidad, tal y como aparece explícita e implícitamente en otros poemas de Darío. Valga como ejemplo «La espiga», ese soberbio soneto de las adiciones de 1901 a Prosas profanas cuyo verso 9 dice: «Pues en la paz del campo la faz de Dios asoma».

La araña debe mostrar servidumbre al Sol, aunque sea, como afirma Marasso, uno de los avatares del demonio que teme al astro rey como el Maligno teme a la Iglesia (223). Van den Broek, por su parte, recuerda la sura de la araña en el Corán «donde se dice que aquellos que toman patronos distintos de Dios tienen por símbolo a la araña» (118). Caracterizada, por tanto, mediante su fealdad y su condición de habitante de lo oscuro, la araña debe someterse al Sol (todo belleza y claridad) y aceptar la forma externa que le ha sido asignada.

En el esquema constructivo es relevante que la araña aparezca al principio, porque a la disposición astral básica con lo solar arriba (v. 1) y lo lunar 
abajo (v. 8) se contrapone otra distribución de índole animal en la cual la araña, siendo el animal infernal más bajo, figura arriba, mientras el oso, que se asemeja al ser humano, aparece abajo junto a la luna.

Afirma Cirlot que en «la araña coinciden tres sentidos simbólicos, que se superponen, confunden o disciernen según los casos, dominando uno de ellos», y estos serían: su capacidad creadora, su agresividad y la tela como red espiral centro del mundo (88). Por tanto, no todas las derivaciones simbólicas de la araña son negativas, como supo plasmar en sus creaciones artísticas Odilon Redon, pintor postimpresionista que muere justo cinco meses después de Darío ${ }^{3}$.

Esas virtudes creativas del arácnido también son recogidas en la mitología clásica, como nos muestra la historia de Aracne, princesa lidia que, por su destreza como tejedora, provocó los celos de Atenea, quien la castigó convirtiéndola en una araña. Del mismo modo, la tarea constante de construcción de la tela nos sugiere la condena de Sísifo, otro castigado por los dioses.

\section{2. "Da tus gracias a Dios, oh, sapo, pues que eres»}

En el segundo verso, al sapo, otro avatar del demonio (Marasso, 223), se le ordena dar las gracias a Dios porque su sentido en el mundo es la mera existencia. Como nos recuerda Cirlot, este animal es «el aspecto inverso e infernal de la rana», por lo que le corresponde «el mismo significado simbólico, pero en aspecto negativo» (400). Aunque, como nos recuerda Biedermann, por ser poco atractivos y por segregar una sustancia corrosiva se los consideraba seres demoníacos, también representaban la matriz (414). Van den Broek señala, del mismo modo, que aunque el sapo habita en las «cavidades oscuras y húmedas de la tierra», también «conjura la lluvia y está, por tanto, relacionado a la emanación del Ser desde lo alto y Divino» (118). En la simbología popular ligada a la religión aparece como «sapo expiatorio»: el alma de una persona que haya muerto sin haber cumplido un voto debe cumplirlo transformado en ese animal y no alcanzará el cielo hasta haber llegado arrastrándose al altar de una iglesia votiva (Biedermann, 414). Es, por ello, como la araña, otro pecador castigado.

3. Afirma Norbert-Bertrand Barbe que el poema de Darío «nos propone un retrato simbolista (a la manera de Odilon Redon) de la araña tejedora y creadora (aludida posteriormente en el poema XXXVI: "Thánatos" de la presente sección), araña que se opone al cisne blanco del poema siguiente XII: "Leda", y a la vaca venusiana del poema XXI, de matiz igualmente filosófico, vaca que prefigura, en su aspecto de: "enorme... bestia apacible" al autóctono y nacional buey del penúltimo poema del libro» (4). 


\section{3. «El peludo cangrejo tiene espinas de rosa»}

Si en los dos primeros versos el contraste entre la divinidad y el animal es máximo (Sol/araña; Dios/sapo), en los dos siguientes, el poeta atenúa la diferencia y matiza concediendo alguna huella de virtud a las otras dos criaturas.

Como señala Biedermann, por su caminar hacia atrás, el cangrejo representa la desgracia (87), pero aquí Darío sabe vincularlo, mediante su saber analógico, con uno de los símbolos de la sublimidad floral. La semejanza que disminuye su negatividad es parcial, por cuanto afecta solo a ciertas protuberancias de este artrópodo que simulan las espinas de las rosas y con las cuales tanto el animal como la planta pueden defenderse de las agresiones de su entorno. Esta primera comparación con uno de los símbolos universales de la belleza y de la poesía inicia una gradación ascendente que nos llevará hasta los atributos especiales del grillo y del oso.

\section{4. «y los moluscos reminiscencias de mujeres»}

Lo mismo sucede con la atenuación aplicada a los moluscos, los cuales, por su condición de invertebrados con simetría bilateral, de cuerpo blando y protegidos por concha (la palabra no es inofensiva), han heredado la belleza de la «celeste carne de la mujer»: una analogía positiva establecida, por tanto, entre los bivalvos y lo uterino eterno en Rubén Darío.

\section{5. "Sabed ser lo que sois, enigmas siendo formas»}

El hallazgo del verso 5 consiste, entre otras cosas, en haber saturado el mismo con varias formas del verbo «ser» en un poema cuyo tema principal es la existencia («ser», «sois», «siendo»), a lo que habría que añadir la segunda persona del presente al final del verso 2 («eres»). Un procedimiento similar reforzado con el uso fónico de las vibrantes simples y múltiples asociadas a todas las vocales del arco se utiliza también en «Lo fatal», pero mientras que este último poema de Cantos de vida y esperanza ha sido interpretado como una declaración de renuncia a la condición de ser humano, este que analizamos supone, al contrario, la aceptación del ser universal.

6.6. «dejad la responsabilidad a las Normas, / que a su vez la enviarán al Todopoderoso...»

Resulta polémica y ambigua la presencia de la palabra «Normas» en el verso 6. Quizá esté ahí por motivos de rima, pues la palabra original sería «Nornas» o «Nornes», las cuales pertenecen a la mitología germánica y equivalen a las 
Parcas latinas o a las Moiras griegas. También serían tres: Urd (el destino), que hila el hilo; Werdandi (el devenir), que lo tuerce; Skuld (el karma), que lo corta (Biedermann, 323). Zepeda-Henríquez vincula a la influencia wagneriana en Darío el empleo de esta referencia y afirma que en estos tres instrumentos de la Divinidad (son intermediarias del «Todopoderoso») se personificaron la moral de la irresponsabilidad, la indiferencia ante el bien y el mal y la visión determinista del universo, conceptos que tendrían su origen «en el armazón literario —rigurosamente literario- de la cosecha operística de Richard Wagner» (69); nos recuerda también que el nombre propio de estas mediadoras es «Nornes» en Wagner y que ejercían «el ministerio demiúrgico de ser responsables de la actividad universal, de la vida misma» (69).

\section{7. «(Toca, grillo, a la luz de la luna, y dance el oso)»}

Al llegar al último verso, bajamos a la tierra y al espacio sublunar, pero ascendemos en la escala de los seres, porque el grillo canta (aunque sin voz), por lo que simboliza la creación musical. Representa también el amor (porque su canto es parte del cortejo), y el amor, como bien sabemos, es el gran tema de la poesía de Rubén Darío en opinión de Pedro Salinas. Ese canto se produce además bajo el misterio de la noche y el Cosmos y pertenece a la música de los seres vivos, a la música del mundo, como nos recuerdan los versos de otro poema perteneciente a la segunda edición de Prosas profanas (1901), el pitagórico «Ama tu ritmo», donde se lee: «Escucha la retórica divina / del pájaro del aire y la nocturna / irradiación geométrica adivina» (vv. 9-11).

También nos remite el grillo al final de la «Sinfonía en grís mayor», poema incluido en este caso en la primera edición de Prosas profanas (1896). Es preciso leer este poema más allá de sus ejercicios sinestésicos, pues se encuentra en él una clara prefiguración de la muerte: «La siesta del trópico. La vieja cigarra / ensaya su ronca guitarra senil, / y el grillo preludia un solo monótono / en la única cuerda que está en su violín» (vv. 30-33).

Dice George Steiner en «¿Por qué lloro cuando canta Arión?», uno de sus Fragmentos un poco carbonizados, que «la música es perfecta y trascendentemente inútil» (67), porque la experiencia musical es «el único encuentro humano con el tiempo que esté libre de temporalidad tal y como lo conocemos en los procesos biológicos y psicológicos» (68). Y en otro de los fragmentos, «Amiga muerte», afirma que: «[1] os grillos cantan con la voz de los poetas difuntos» (79).

En este verso final no solo hallamos, como afirma Van den Broek Chávez, «la noción pitagórica de la música del mundo, encarnada en el canto del grillo y la danza del oso» (119), sino que en él desemboca, en coherencia con 
todo el poema al que pone broche, un tópico clásico que tiene su origen en el pensamiento griego, como es el del Deus artifex. Según las numerosas exposiciones críticas de este tema, Platón, la Biblia y el cristianismo medieval son eslabones de una larga cadena que será reformulada en el Renacimiento italiano por algunos estudiosos del arte. Dios es un creador, pero los seres humanos también lo son en otro nivel. El «Sol», «Dios» o el «Todopoderoso» de nuestro poema crean la naturaleza como un ideal eterno, mientras que los seres, como imitadores de la naturaleza, poseen su cuota de creatividad dentro de la misma pero de una manera incompleta, ya que la propia naturaleza no puede ser nunca semejante a la esencia ideal. Por ello, todos los seres de este poema, incluso la misma luna que recibe una luz prestada, son instrumentos de la armonía cósmica pero en un nivel jerárquico vicario. Contra este planteamiento de corte antiguo se rebelaron los teóricos renacentistas apelando a una idea más cercana a lo ideal y alejada de lo formal, la noción de concetto, según la cual es posible situarse en un plano de igualdad con respecto al «Todopoderoso». De ese modo, el artista, como nuevo Prometeo, puede aspirar a la perfección mejorando la naturaleza.

Ya aludimos a la luna, asociada aquí a la imaginación y a la fantasía y cuya aparición refuerza la circularidad filosófica del poema mediante la mejor representación del misterio de la vida (luz) recibida de un ser superior (Sol).

No obstante, para el desarrollo de algunas ideas expuestas en los párrafos anteriores, ninguna aparición es más espectacular que la del oso, uno de los animales frecuentemente citados en la poesía de Darío ${ }^{4}$. Simbólicamente está vinculado a la luna (Cirlot, 291), pues, como ella, alterna apariciones y desapariciones (cuando hiberna). Al ser el único mamífero mencionado en el poema, representa con claridad al ser humano, no solo por su condición de mamífero sino por otras semejanzas, como el hecho de que pueda erguirse sobre sus dos patas. Pero su valor principal en este cierre del poema reside en la «locura armoniosa» del baile, el placer de la danza como algo vitalmente humano y la noción hedonista de la misma vida como danza. Por ello, las lecturas psicológicas del símbolo asocian al oso con los peligros del inconsciente (Cirlot, 351) que provoca la música, los aspectos negativos, en terminología de Jung, de la personalidad superior (Biedermann, 340) que tanto hicieron gozar y sufrir a Darío. En ese sentido la aparición del animal al final del poema puede interpretarse como una presencia ominosa que simboliza las ataduras

4. Sigo aquí el estudio pionero, aunque esencialmente técnico, de Francisco Gutiérrez Soto que tengo la intención de desarrollar interpretativamente en futuras investigaciones. 
del ser humano, su condición de esclavo obligado a bailar bajo una luz secundaria al son de una música cuyo origen desconoce.

En sus memorias, Hicth-22, el gran Christopher Hitchens reflexiona sobre el espanto de la tortura a partir de los testimonios de Jacobo Timerman (editor secuestrado y torturado del periódico bonaerense La Opinión), quien levantó acta de la ignominia en Preso sin nombre, celda sin número: «Flaubert tenía razón cuando dijo que la palabra humana es como una olla rota sobre la que marcamos ritmos toscos para que bailen los osos, cuando querríamos conmover a las estrellas» $»^{5}$ (237-238). Encuentro aquí, en esta referencia, no solo una convergencia con el verso final del poema, sino con el significativo tópico de la poesía y la filosofía moderna que nos habla de las limitaciones del lenguaje, algo que el propio Darío había expresado de modo magistral en el último poema de Prosas profanas (1901): «Yo persigo una forma que no encuentra mi estilo».

Sobre el poder y las miserias de la música, también nos recuerda Steiner que «Valéry sugiere que el pensamiento debería bailarse» (68) y que, por desgracia, «[s] omos "señores de la danza", pero bailamos en torno al becerro de oro, tal y como lo hicieron aquellos lejanos intermediarios de la salvación» (53).

\section{Sentido (más o menos) filosófico}

Con un dominio soberbio de las técnicas literarias más actuales (brevedad, levedad, precisión) y derramando una cascada de sugerencias, Darío expresa en este poema que la esencia secreta, enigmática, es más relevante que la apariencia. Ya lo había escrito antes de 1901 en «La espiga», donde «los dedos del viento» [...] «trazan sobre la tela azul del firmamento / el misterio inmortal de la tierra divina / y el alma de las cosas [...]», sin que pareciera haberlo advertido diez años después Enrique González Martínez en su poema más famoso donde pretendía que los poetas le torcieran el cuello a un «cisne de engañoso plumaje» que ya hacía tiempo que se había convertido en un habitante de lo oscuro.

Aunque a veces nos cueste admitir esto, no hay ser vivo repugnante: todas las criaturas son emanaciones y signos del misterio, formas que remiten a otras en la jerarquía de los seres, manifestaciones de lo uno y absoluto. Ante el enigma, nuestra elección es vivir, cantar y bailar. Por otro lado, somos osos condenados a danzar en una fiesta sin sentido. Ese final entre paréntesis, tan

5. La frase pertenece a Madame Bovary, que cito por la versión de Carmen Martín Gaite que fue en la que leí la novela por primera vez: «la palabra humana es como una especie de caldero roto con en el que tocamos una música para hacer bailar a los osos, cuando lo que nos gustaría es conmover a las estrellas con su son» (227). 
característico de muchos poemas de Darío, como «La dulzura del ángelus» o «Caracol», puede suponer, también, en coherencia con la ambigüedad que vertebra el poema, una ruptura radical con la interpretación optimista del mismo y con el conformismo de los siete primeros versos, por cuanto puede ser interpretado como la asunción por parte del ser humano de su destino de oso esclavizado o marioneta del destino.

Es cierto que el aparente optimismo de este poema contrasta con el pesimismo de otros muchos de Cantos de vida y esperanza, como los dos «Nocturno[s]»o «Lo fatal», pero ello no debe hacernos olvidar que su lectura interpretativa podría ser más sesgada: un himno a la existencia es también una reflexión sobre su reverso. Como afirma Steiner, «toda existencia, todo lo que vive, es el prólogo a una muerte segura» (75) y este poema es, con claridad y oscuridad a un tiempo, una indagación sobre el hueco, como en la mejor tradición neobarroca, pero muchos años antes. Cuando Darío canta a la existencia al fondo acecha Ella, pues «[a]segurar que algo existe es también postular que quizá no exista [...]. Toda sustancia está entrelazada con la inexistencia, con el lado oscuro de la luna». La no existencia es algo que no puede ser expresado ni dicho pues quizá, como ya planteó Parménides, no hay existencia fuera de la gramática (Steiner, 13).

«Filosofía», uno de los poemas más visionarios de Darío, nos exalta y nos limita, nos eleva y nos entierra, nos apega «a la luz de la luna», reflejo del Sol, el único ámbito donde pueden mostrarse las emanaciones de lo desconocido, pues los seres vivos existimos y debemos desear existir, como la música, ser en sí misma, frente al lenguaje, máscara del ser.

Los que se inician académicamente en los estudios literarios suelen plantear a los docentes, con cierta frecuencia, sus legítimas dudas sobre si el creador pensó conscientemente lo que el estudioso o el lector creativo interpretan. La primera respuesta es que los poetas o no piensan o piensan cantando y diciendo; la segunda es que, en defensa de la hermenéutica, nuestra obligación estética y moral es la de especular y llenar la nada en esa frontera entre el lenguaje y el silencio. ¿Estaba ebrio Darío, como quería Baudelaire, cuando escribió este poema? ¿Qué licor sagrado había bebido? No debe perderse ni un segundo en responder a esa pregunta, pues «la creatividad de primer orden - a menudo comparada con divinidad - escapa al entendimiento, no digamos ya a la predicción» (Steiner, 29). Y como dijo el propio Darío: «la primera ley, creador: crear. Bufe el eunuco» $(1992,38)$. 


\section{Bibliografía citada}

Allegra, Giovanni, El reino interior. Premisas y semblanzas del modernismo en España, trad. Vicente Martín Pindado, Madrid, Encuentro, 1986.

BARBE, Norbert-Bertrand «La dualidad ontológica en Cantos de vida y esperanza», Cátedra, 12 (2005), pp. 1-5; <revistacatedra.unan.edu.ni/index.php/catedra/ article/download/133/117> [consulta: 20 junio 2016].

Biedermann, Hans, Diccionario de símbolos, Barcelona, Paidós, 1993.

Bourne, Louis, Fuerza invisible. Lo divino en la poesía de Rubén Darío, Málaga, Universidad, 1999.

Calvino, Italo [1998], Seis propuestas para el próximo milenio, Nota prel. Esther Calvino, ed. César Palma, trad. Aurora Bernárdez y César Palma, Madrid, Siruela, 2010.

Castellanos, Rosario [1972], Poesía no eres tú. Obra poética (1948-1971), México, Fondo de Cultura Económica, 2004.

Cirlot, Juan Eduardo, Diccionario de símbolos, Barcelona, Círculo de Lectores, 1998.

DARío, Rubén, Poesía. Libros poéticos completos y antología de la poesía dispersa, est. prel. Enrique Anderson Imbert, ed. Ernesto Mejía Sánchez, México, Fondo de Cultura Económica, 1952.

- El modernismo y otros ensayos, sel., prol. y notas Iris M. Zavala, Madrid, Alianza, 1989.

- Prosas profanas, ed. José Olivio Jiménez, Madrid, Alianza, 1992.

- Azul... Cantos de vida y esperanza, ed. José María Martínez, Madrid, Cátedra, 1995.

- Poesía, ed. Julio Ortega, colab. Nicanor Vélez, Barcelona, Galaxia GutenbergCírculo de Lectores, 2007.

- Obra poética, ed. José Carlos Rovira, colab. Sergio Galindo, Madrid, Fundación José Antonio de Castro, 2011.

Flaubert, Gustave, Madame Bovary, trad. Carmen Martín Gaite, Barcelona, OrbisOrigen, 1982.

GutiéRREZ Soto, Francisco, «El bestiario en la poesía de Rubén Darío», Anales de Literatura Hispanoamericana, 26.1 (1997), pp. 13-28.

Hitchens, Christopher, Hitch-22. Memorias, trad. Daniel Rodríguez Gascón, Barcelona, Debate, 2011.

IRBY, James, «El Ibis de Darío: indagación de un poema», La Habana Elegante, 51 (2012); <http://www.habanaelegante.com/Spring_Summer_2012/Dicha_Irby. html> [consulta: 20 junio 2016].

JRADE, Cathy Login, Rubén Darío y la búsqueda romántica de la unidad. El recurso modernista a la tradición esotérica, trad. Guillermo Sheridan, México, Fondo de Cultura Económica, 1986. 
Juan Ramón Jiménez Papers; <https://lccn.loc.gov/mm81092429> [consulta: 20 junio 2016].

MARASSO, Arturo, Rubén Darío y su creación poética, La Plata, Facultad de Humanidades y Ciencias de la Educación de la Universidad de La Plata, 1934.

MonsivÁIs, Carlos, Días de guardar, México, Era, 1970.

OtA, Seiko, José Juan Tablada: su haikú y su japonismo, México, Fondo de Cultura Económica, 2014.

Paz, Octavio, Libertad bajo palabra [1935-1957], ed. Enrico Mario Santí, Madrid, Cátedra, 1988.

Rovira, José Carlos, «De nuevo sobre el archivo de Miguel Hernández», en Bénédicte Vauthier y Gimena Gamba Corradine (eds.), Crítica Genética y edición de manuscritos hispánicos contemporáneos. Salamanca, Universidad, 2012, pp. 209-234.

SALINAS, Pedro [1948], La poesía de Rubén Darío. Ensayo sobre el tema y los temas del poeta, Barcelona, Seix Barral, 1975.

SAZ, Sara, "El haikú en la poesía latinoamericana», en Toshiaki Arimoto, María Pilar García-Escudero \& Takamasa Inui (eds.), Japón y el mundo hispánico: enlaces literarios, culturales y lingüisticos, Nagoya (Japón), Asociación Europea de Profesores de Español, 2004, pp. 187-197.

SEgovia, Tomás, «Dos veces Cernuda», en Sobre exiliados, pról. José María Espinasa, México, El Colegio de México, 2007, pp. 85-120.

SteINER, George, Fragmentos un poco carbonizados, trad. Laura Emilia Pacheco, Madrid, Siruela, 2016.

VAN DEN BRoek ChÁVEZ, A. R., Esoterismo y modernismo: Ruben Darío y Antonio Machado; <http://dare.uva.nl/record/1/179949> [consulta: 20 junio 2016].

ZEPEDA-HENRíQUeZ, Eduardo, "Génesis y éxodo de la palabra dariana», Anales de Literatura Hispanoamericana, 26.1 (1997), pp. 67-91. 